Article

\title{
Analysis of the Thermal Characteristics of Welding Spatters in SMAW Using Simplified Model in Fire Technology
}

\author{
Yeon Je Shin $\mathbb{D}^{\circ}$ and Woo Jun You * \\ Department of Architecture \& Fire Safety, Dongyang University, Yeongju 36040, Korea; jeje5842@naver.com \\ * Correspondence: wjyou@dyu.ac.kr; Tel.: +82-54-630-1297
}

Received: 16 February 2020; Accepted: 22 April 2020; Published: 4 May 2020

\begin{abstract}
In this study, the thermal characteristics of welding spatters were analyzed to predict the risk of fire spread in the shield metal arc welding. The mean diameters and the distribution shapes of the particles were investigated with the variation of the distribution coefficients using the modified gamma distribution function. To quantify the heat source of the welding spatters, the previous empirical equation for the heat transfer coefficient of Ranz and Marshall was analyzed regarding the particle velocity and surface temperature. The order of magnitude for the convection and the radiation were as performed to the particles and the base metal, respectively. The results, which are only valid for $T_{p, m}=750 \mathrm{~K}$ and $T_{b, s}=2300 \mathrm{~K}$, show that the radiation term is only $10 \%$ for a particle but the convective term is only $6 \%$ for the base metal. Finally, the simplified model for the temperature of the welding spatters was obtained and the validation results were within $\pm 13 \%$. The variations of electrical power, droplet size, number of particles, and surface temperature were systematically analyzed with the prediction model. The importance of safety conditions to prevent the fires spread by welding spatter was suggested with electrical power, particle velocity, and numerical density of the particles.
\end{abstract}

Keywords: welding spatter; distribution; shield arc metal welding; particle heat transfer; fire risk

\section{Introduction}

Welding can be divided into fusion, pressure, and soldering by applying heat and pressure to the same or different types of metal materials to bond the solids together [1-3]. The fusion method uses an electrode and an electrical power source to create a heat source, resulting in the base metal reaching more than melting temperature and bonding together. Fusion types include gas metal arc welding (GMAW) and shield metal arc welding (SMAW) [4-6]. The GMAW is an arc welding process that uses a plasma arc between a continuous, consumable filler-metal electrode and the weld pool $[7,8]$. The SMAW, which is the most widely used in building construction, applies electrical power between the metals, such as carbon steels alloy steels nickel and copper alloys, and the electrode to generate arc heat, heating and binding the welds [9-11]. In this process, however, the unbound metals fall off and generate numerous or large particles due to the high temperature of the arc discharge, also known as welding spatters. The spread of these particles can make contact with a combustible material and, if the particles are above the ignition point of the material, can cause a fire. The fire hazards from the SMAW at building construction sites can occur when welding spatters make contact with the inward of a pipe or other enclosed space filled with the flammable vapor or liquid [9-13]. In addition, flammable materials, such as foam urethane or sandwich panels, can be ignited by welding spatters due to thermal storage [13-15]. In accordance with previous research, particles from 0.1 to $3 \mathrm{~mm}$ can be dispersed horizontally from the work from 11 to $15 \mathrm{~m}$, igniting flammable materials [13-18]. Previous studies 
have reviewed major fire accidents caused by welding spatters $[19,20]$ and the thermal characteristics of the particle distributions is one of the most important subjects in fire engineering.

Chol et al. numerically investigated the movement of the metal particles from the GMAW to be $150 \mathrm{~A}$ and $300 \mathrm{~A}$ [21]. The predictions using the VOF (Volume of Fluid) method for spray velocity, pressure and diameter of particles for the two values of current roughly agree with Kim's research [17]. However, the heat transfer between electrodes and base metal was not considered. Wang et al. [22] used high-speed photography, laser-shadow imaging, and metallographic analysis to validate the simulation results of the GMAW. The results were in broad agreement with experiments despite the assumptions that no drag effects on the droplet surface. Hu et al. analyzed the fluid flow and heat transfer in the GMAW with arc plasma [7]. The transient distributions of current density, arc temperature, and arc pressure were studied, with the assumption that Gaussian profiles were presented to explain the droplet transfer and deformed weld pool surface for GMAW. However, the thermal characteristics of the SMAW is still slow to progress since the distribution of the welding spatters are affected by welders' experiences or circumstances [12]. The electrode used in SMAW is thicker and the arc instability relies on the welders' sensory evaluations unlike the electrode used in GMAW [4]. This causes significant differences for the thermal-fluid characteristics of welding spatters in the fire technology. While the GMAW generates relatively small welding spatters since it is welded to thin electrodes continuously supplied by gas and heat sources such as plasma, the SMAW can generate large particles as it is welded with thick electrodes supplied with fluctuating heat sources [4-6]. The previous studies of the GMAW may predict the transfer phenomenon for welding spatters, but only complex computations can obtain numerical results regarding that the phenomenon. These issues would make it difficult to analyze the risk of fire spread. To overcome these difficulties, a simplified method for solving the heat transfer equation must be developed to explain, not only the thermal characteristics of welding spatters but also the distributions of particles in SMAW. In this study, the simplified prediction model of the surface temperature of welding spatters by SMAW is presented in accordance with electrical power, welding speed and a time, using energy conservation equation.

\section{Materials and Methods}

\subsection{Heat Transfer Phenomenon of Welding Spatters}

The thermo-fluid characteristics of the distribution particles, which are generated by welding spatters from the SMAW, depends on electronic power, base metal (material) and electrode (material, welding speed and contact angle between the base metal and electrode) as shown in Figure 1 [17,18]. The dependent variables are summarized as temperature, relative velocity, diameter, and numerical density of particles. Thus, the energy balance for the control volume of the base metal can be expressed as:

$$
\Delta \dot{E}_{s t}=\dot{E}_{\text {in }}+\dot{E}_{g}-\dot{E}_{\text {out }}
$$

where $\Delta \dot{E}_{s t}, \dot{E}_{g}, \dot{E}_{\text {in }}$ and $\dot{E}_{\text {out }}$ are the stored thermal and mechanical energy, thermal, and mechanical energy generation and thermal and mechanical energy transport across the control surfaces, i.e., the inflow and outflow terms, respectively. The flammable materials, which are continuously heated for a sufficient time as shown in Figure 1, could combust while the base metal maintains its melting temperature. Thus, the first term of Equation (1) can be simply assumed as Equation (2) for the steady state regarding the risk of fire spread.

$$
\dot{E}_{s t}=m_{b} c_{b, p} \frac{d T_{b}}{d t} \equiv 0
$$


where $m_{b}, c_{b, p}, T_{b}$, and $t$ denote mass, specific heat, and temperature for the base metal and time, respectively. The thermal and mechanical energy transference to the base metal for the SMAW is mainly produced by electrical power. Thus, Equation (3) can be assumed as,

$$
\dot{E}_{i n}=\eta(V \times I)
$$

where $\eta, V$, and I denote that efficiency of the electrical power, voltage, and current, respectively. When the heat source from the electrical power is transferred to the base metal, the surface temperature can be up to the melting temperature during the welding process [5,7]. The base metal can be thought of as at constant temperature since the equilibrium of the heat transfer by convection and radiation maintains the melting temperature of the base metal. The second assumption is very thin control volume of Figure 1 and the heat transfers to the base metal. Thus, the heat generation $\dot{E}_{g}$ for the base metal can be regarded as:

$$
\dot{E}_{g}=-\left[h_{b} A_{b, s}\left(T_{b, s}-T_{\infty}\right)+\sigma \varepsilon A_{b, s}\left(T_{b, s}^{4}-T_{s u r}^{4}\right)\right]
$$

where $h_{b}, A_{b, s}, T_{b, s}, T_{\infty}$ and $T_{s u r}$ denote that heat transfer coefficient for the flat plate, surface area, surface temperature for base metal, free stream, and surrounding temperature, respectively. If the surface temperature of the base metal remains constant during the welding process, the heat transfer coefficient $h_{b}$ can be approximated as $10 \mathrm{~W} / \mathrm{m}^{2}-\mathrm{K}$ [23]. The amount of energy released by the particle distribution can be expressed as:

$$
\dot{E}_{\text {out }}=\sum_{i=1}^{\infty} E_{p, i}=\sum_{i=1}^{\infty} n_{i} q_{p, i}^{\prime \prime} A_{i}
$$

where the subscript $i, n_{i}, q_{p, i}^{\prime \prime}$ and $A_{i}$ mean that each size of the particles during the welding process, the number of particles, the heat flux, and the surface area for ith particle size. Therefore, Equation (1) can be rearranged as

$$
\eta \times P_{e}=\left[h_{b} A_{b, s}\left(T_{b, s}-T_{\infty}\right)+\sigma \varepsilon\left(T_{b, s}^{4}-T_{\text {sur }}^{4}\right)\right]+\sum_{i=1}^{\infty} n_{i} q_{p, i} A_{i}
$$

where the left-hand side of Equation (6) explains the electrical power $\left(P_{e}=V \times I\right)$ from the electrode to the base metal and the right-hand side explains the heat transfer of base metal and the particles, respectively.

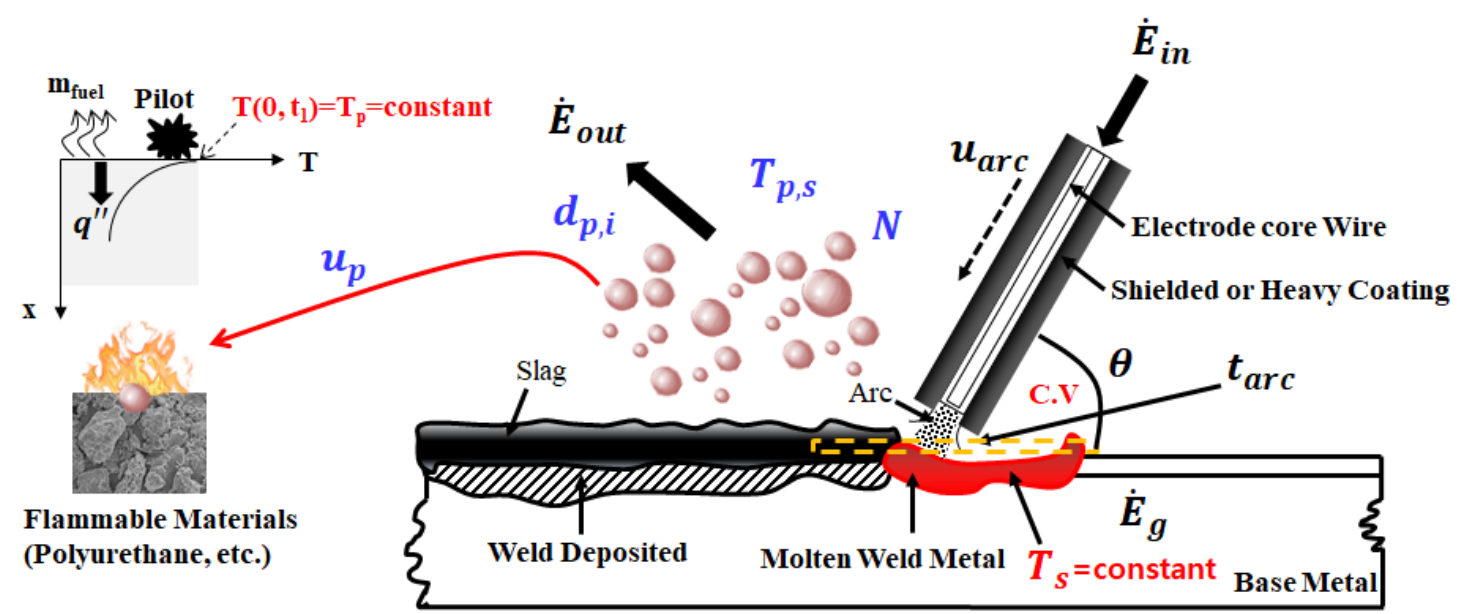

Figure 1. The schematic diagram of welding spatters by the SMAW and the assumptions for temperature of the particles and the base metal. 


\subsection{Momentum Equation for Simplification}

The velocity distributions of the heated particles should consider the drag coefficient and the dynamic viscosity of air and density $[7,8,14]$. As temperature increases, so does the viscosity; meanwhile, the density decreases for the ideal gas. This means that the initial particle velocity decreases since the drag coefficient increases by the Reynolds number $[5,14]$. However, in the author's knowledge, the initial velocity depends on the welding conditions such as electrical power, the angle of contact between the electrode and base metal for the specified properties of each material and the thermal time constant of the base metal surface. In addition, the worst case of the fire spread by welding is the maximum velocity for steady state. In this study, the most important objective is the prediction of the fluid and the thermal characteristics of welding spatters which can ignite surrounding flammable materials. Thus, the transient and the velocity variations during the spray time are not considered.

\subsection{Distribution Model of Welding Spatters}

The size distribution of particles produced by the SMAW is approximated by a Deirmenjian modified gamma function distribution, which is the most widely used in poly dispersion systems as denoted below $[24,25]$.

$$
n(r)=a r^{\alpha} \exp \left(-b r^{\gamma}\right)
$$

where $a, b, \alpha$ and $\gamma$ are distribution coefficients for the welding spatters. In general, $\alpha$ is an integer and the distribution coefficients are dependent on each other [24]. Since Equation (9) should have three zeros (at $r=0, r=\infty$ and $r=r_{m}$ ), the constant $b$ can be determined as $b=\alpha /\left(\gamma r_{m}^{\gamma}\right)$ at $r=r_{m}[24,25]$. The relation of the numerical density (number of particles per unit volume) and the normalized distribution of $n(r)$ is defined as $n(r)=f_{\exp }(r) N$ [26]. Thus, the coefficient $a$, the number density $N$ and the normalized modified distribution $f_{\exp }(r)$ can be obtained as Equations (8)-(10) [25]:

$$
\begin{gathered}
a=N \times \gamma b^{(\alpha+1) / \gamma} / \Gamma\left(\frac{\alpha+1}{\gamma}\right) \\
N=\int_{0}^{\infty} n(a) d a=\int_{0}^{\infty} f(a) N d a=A \Gamma\left(\frac{\gamma+1}{\delta b(\gamma+1)}\right) \\
f_{\exp }(r)=a C_{0} \times r^{\alpha} \exp \left(-b r^{\gamma}\right)
\end{gathered}
$$

where $\Gamma$ and $N$ are gamma function and number of particles per unit volume. The symbol $A$ in Equation (9) can be determined by the number density $N$ for $a^{\prime}=a / N$ and the experimental constant $\left(C_{0}\right)$ and substitute $f(r)$ as denoted in Equation (10). Studies have examined the fitting process of the measured distributions [26]. The droplet mean diameter can be obtained from Equation (9) with various methods such as SMD (Sauter Mean Diameter) as shown in Figure 2 [27]. Therefore, as denoted in Equation (11), the summation of volume for each particle should be equal to the volume of particle mean diameter multiplied by the number.

$$
V_{\text {total }}=\sum_{i=1}^{\infty} \frac{\pi}{6} d_{p, i}^{3} \times n_{i}=\frac{\pi}{6} \bar{N} d_{p, m}^{3}
$$

where $V_{\text {total }}, d_{p, i}, d_{p, m}$ and $\bar{N}$ means the total volume, the diameter of each particle, the mean diameter of particles and the number of particle mean diameter, respectively. Thus, $d_{p, m}$ and $\bar{N}$ are related with:

$$
\bar{N}=\frac{6 V_{t o t a l}}{\pi d_{p, m}^{3}}
$$




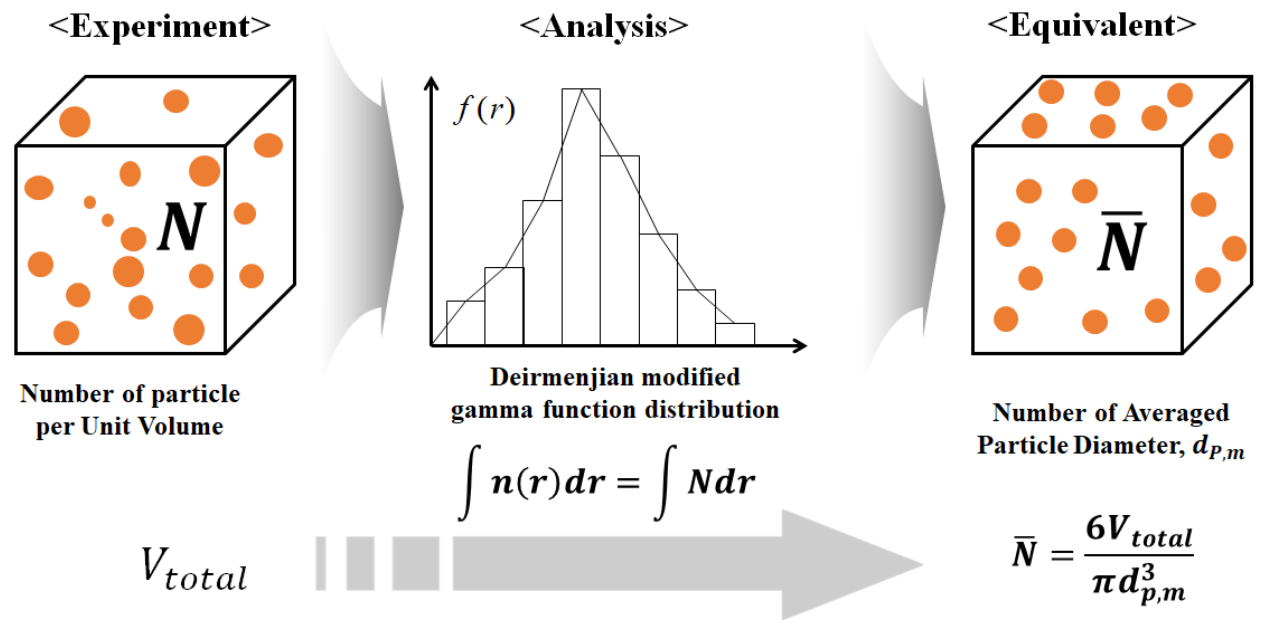

Figure 2. The schematic diagram of the analytic method for distribution of the particles.

Finally, $\dot{E}_{\text {out }}$ in Equation (5) can be replaced by:

$$
\dot{E}_{\text {out }}=\sum_{i=1}^{\infty} n_{i} q_{p, i}^{\prime \prime} A_{i}=\bar{N} \times \bar{q}_{p, d_{m}}^{\prime \prime} A_{d_{m}}
$$

where $\bar{q}_{p, d_{m}}^{\prime \prime}$ and $A_{d_{m}}$ denote the heat flux and the surface area of the mean diameter, respectively.

\subsection{Considering of Heat Transfer Coefficient}

The heat transfer from the spray of spherical particles has the conservation of energy equation as denoted in Equation (14) by the convection for the free stream at the particle surface and the radiation with surrounding,

$$
\bar{q}_{p, d_{m}}^{\prime \prime}=h\left(T_{P, s}-T_{\infty}\right)+\varepsilon \sigma\left(T_{P, s}^{4}-T_{\text {sur }}^{4}\right)
$$

where $h$ is the heat transfer coefficient. Several researchers have proposed the empirical equation of the convective heat transfer coefficient. In this study, Equation (15) is suggested by Ranz and Marshall [28], which is recently applied to investigation of Song et al. [14] and is analyzed with particle diameter and particle surface temperature as the Reynolds number increases. Table 1 denotes the thermal properties for determining the Reynolds number, the Prandtl number and the heat transfer coefficient when the particle diameters are $d_{p, m}=0.001 \mathrm{~m}$ and $d_{p, m}=0.003 \mathrm{~m}$, respectively.

$$
N u_{D}=\frac{h d_{p, m}}{k}=2+0.6 \operatorname{Re}_{D}^{0.5} \operatorname{Pr}^{1 / 3}
$$

where $N u_{D}, h, R e_{D}$ and $P r$ of Equation (15) denote the overall Nusselt number, the conductive heat transfer coefficient, Reynolds number, and Prandtl number. The properties of density $(\rho)$, thermal conductivity $(k)$, specific heat $\left(C_{p}\right)$ and viscosity $(\mu)$ for Reynolds number and Prandtl number are considered at film temperature $\left(T_{\text {ref }}=\left(T_{p, s}+T_{\infty}\right) / 2, T_{\infty}=273 \mathrm{~K}\right)[14,29]$.

Figure 3 denotes the previous investigations on the correlation between the critical temperature (for ignition of flammable materials) $\left(T_{p, c}\right)$ and one particle size $\left(d_{p, c}\right)$. As shown in the figure, Urban [30] et al. experimentally analyzed the fire spread in power grass blend according to particle size (marked with triangle). Song [14] and Hadden [31] applied the Frank-Kamenetskii equation on polyurethane foam and Powder cellulose to analyze the critical of fire spread, respectively (marked with rectangular and circle). In author's knowledge, the critical temperature of combustible materials may vary depending on the particle distribution of welding spatters. In addition, the ignition boundary could be affected by the particle velocity as well as the particle diameter due to the heat transfer of the particle $[14,30,31]$. Therefore, in this study, the lowest temperature boundary of J. Song et al. [14] is 
assumed with the critical temperature for fire spread as denoted in Equation (16), which is derived from curve-fitting, and the effects of particle diameter on the heat transfer are investigated.

$$
d_{p, c}=1.65 \times 10^{32} T_{p, c}^{-11.32}
$$

Table 1. Results of the coefficients of the distribution function.

\begin{tabular}{cccccc}
\hline Fixed Value & $\mathbf{a}$ & $\mathbf{b}$ & $\boldsymbol{\alpha}$ & $\boldsymbol{\gamma}$ & $\mathbf{d}_{\mathbf{p}, \mathrm{m}}$ \\
\hline \multirow{4}{*}{$\alpha=2$} & 0.0090 & 0.0030 & 2.0000 & 3.0000 & 6.0571 \\
\cline { 2 - 6 } & 0.0418 & 0.0030 & 2.0000 & 4.0000 & 3.5930 \\
\cline { 2 - 6 } & 0.1029 & 0.0030 & 2.0000 & 5.0000 & 2.6606 \\
\cline { 2 - 6 } & 0.1854 & 0.0030 & 2.0000 & 6.0000 & 2.1926 \\
\cline { 2 - 6 } & 0.2808 & 0.0030 & 2.0000 & 7.0000 & 1.9173 \\
\hline \multirow{5}{*}{$\gamma=2$} & 0.3821 & 0.0030 & 2.0000 & 8.0000 & 1.7382 \\
\hline & 0.4845 & 0.0030 & 2.0000 & 9.0000 & 1.6134 \\
\cline { 2 - 6 } & 0.0124 & 0.0030 & 1.0000 & 4.0000 & 3.0214 \\
\hline & 0.0042 & 0.0030 & 2.0000 & 4.0000 & 3.5930 \\
\hline & 0.0012 & 0.0030 & 3.0000 & 4.0000 & 3.9764 \\
\hline & 0.0003 & 0.0030 & 4.0000 & 4.0000 & 4.2729 \\
\hline & 0.0000 & 0.0030 & 6.0000 & 4.0000 & 4.7287 \\
\hline & 0.0000 & 0.0030 & 7.0000 & 4.0000 & 4.9145 \\
\hline
\end{tabular}

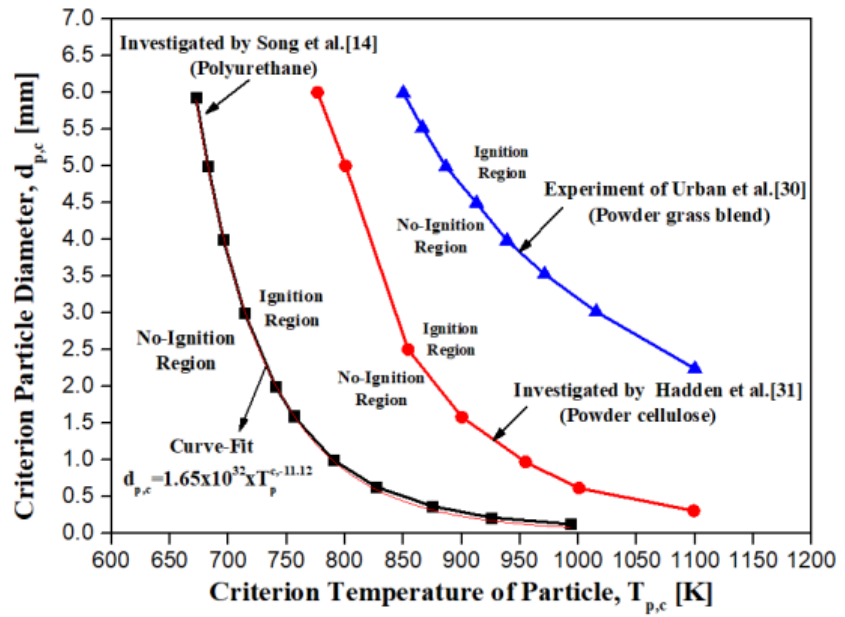

Figure 3. Investigation of the particle diameter and temperature criteria from previous results $[14,30,31]$.

Figure 4 shows results of the overall Nusselt number and the heat transfer coefficient of particles as the Reynolds number increases when $T_{r e f}=525 \mathrm{~K}$ and $1315 \mathrm{~K}, d_{p, m}=1 \mathrm{~mm}$ and $3 \mathrm{~mm}$, respectively. As shown in the figure, the overall Nusselt number increases proportionally with the Reynolds number regardless of the particle diameter and temperature. However, for the fixed values of $d_{p, m}$ and the Reynolds number, as the particle temperature increases, the heat transfer coefficient increases due to the increase in viscosity and the decrease in density. In addition, for the fixed values of $T_{\text {ref }}$ and the Reynolds number, as the particle diameter decreases, the heat transfer coefficient inversely increases proportionally to the particle diameter. 


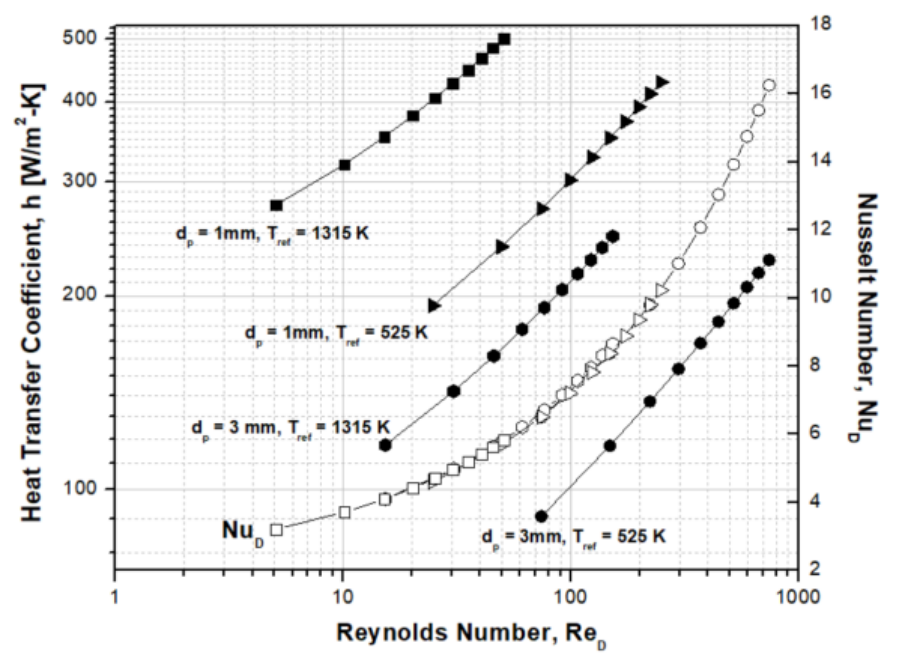

Figure 4. The Nusselt number and heat transfer coefficient with the particle diameter and temperature.

\subsection{The Order of Magnitude for Particle and Base Metal}

The governing equation of Equation (6) cannot be derived analytically due to the radiation term of particle as denoted in Equation (14). To predict the particle temperature with simple equation, the quantities of heat amount are compared with the method of the order of magnitude for the base metal and particle diameter, respectively [32]. Since the base metal can be welded when the melting temperature reaches about $\sim 2327 \mathrm{~K}$ while the particle temperature can ignite the flammable materials more than $\sim 750 \mathrm{~K}$ as referred to in [14]. The interest region of temperature can divide into $\sim 750 \mathrm{~K}$ for particle and $\sim 2327 \mathrm{~K}$ for base metal.

Figure 5 shows the comparative results of the radiative and the convective heat transfer for one particle at $d_{p, m}=3 \mathrm{~mm}$ and $u_{p, m}=10 \mathrm{~m} / \mathrm{s}$. Thus, the heat transfer coefficient, $h$ can be obtained from the Reynolds number $\left(\operatorname{Re}_{D}=\rho u_{p, m} d_{p, m} / \mu\right)$ in Equation (15) [14,15]. The radiative term more rapidly increases than the convective term as particle temperature increases; the radiative term is higher than the convective term at $2240 \mathrm{~K}$. The risk of fire spread by welding particles, however, is about $T_{p, s}=750 \mathrm{~K}$ at $d_{p, m}=3 \mathrm{~mm}$. The radiative term is only $10 \%$ and the convective term is more dominant at $T_{p, s}=750 \mathrm{~K}$. Therefore, the assumption that the convective heat transfer for the particles are mainly an influence on the particle's temperature is a reasonable one. Thus, Equation (14) can be simplified as below,

$$
\bar{q}_{p, d_{m}}^{\prime \prime} \equiv-h\left(T_{P, s}-T_{\infty}\right)
$$

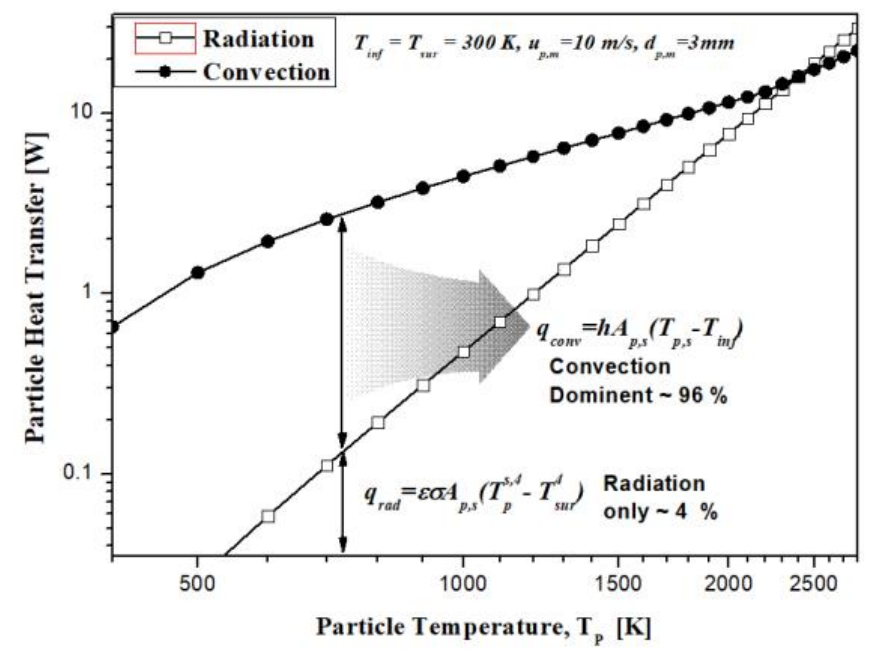

Figure 5. Comparison of the convection and the radiation of the particle. 
Figure 6 shows the comparative results of the radiative and the convective heat transfer for the base metal at using $\varepsilon=0.3, \sigma=5.67 \times 10^{-3} \mathrm{~W} / \mathrm{m}^{2} \cdot \mathrm{K}^{4}$ and $d_{p, m}=3 \mathrm{~mm}$. Since the heat transfer coefficient is $h_{b, s}=10 \mathrm{~W} / \mathrm{m}^{2}-\mathrm{Ks}$ for the plate [23], the convective term is less than the radiative term and more than $T_{p, s}=700 \mathrm{~K}$. Contrary to the heat transfer of one particle, the surface temperature of the base metal is more than $2300 \mathrm{~K}$ and the convective term is only $6 \%$. Thus, the radiative term is mainly an influence on the surface temperature of the base metal. Equation (4) can therefore be simplified as follows,

$$
\dot{q}_{g}^{\prime \prime}=\frac{\dot{E}_{g}}{A_{b, s}} \equiv \sigma \varepsilon\left(T_{b, s}^{4}-T_{\text {sur }}^{4}\right)
$$

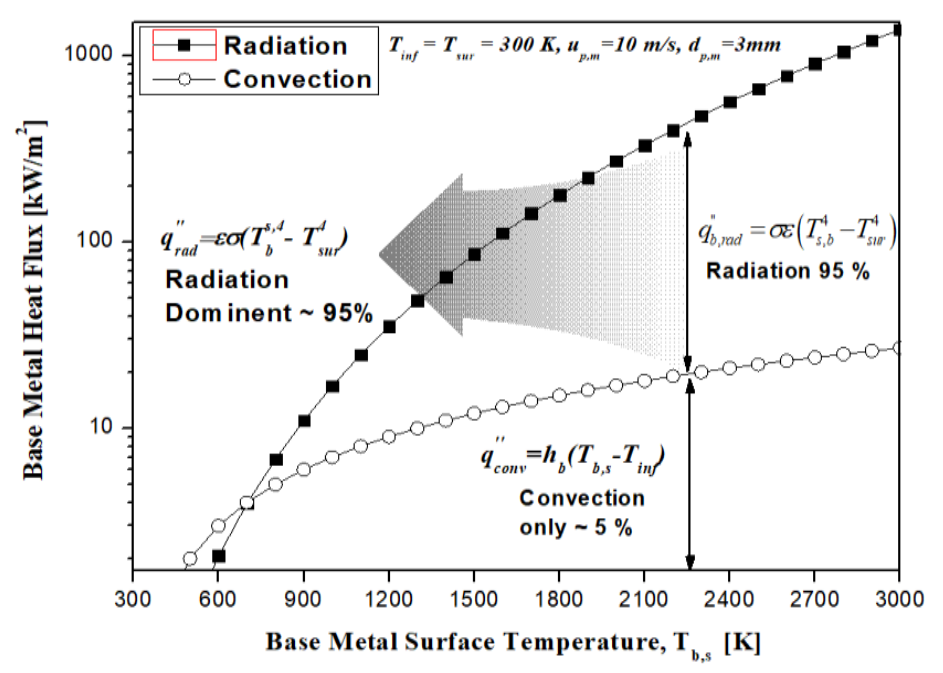

Figure 6. Comparison of the convection and the radiation of the base metal.

\subsection{Model Equation for Surface Temperature of the Particles}

From the analysis of the heat transfer for the particle and base metal, Equation (6) for the energy balance in the SMAW can be rearranged as Equation (19) using with Equations (3), (17) and (18) for the steady state condition.

$$
\eta \times P_{e}=\sigma \varepsilon A_{b, s}\left(T_{b, s}^{4}-T_{s u r}^{4}\right)+\bar{N} h A_{P, s}\left(T_{P, s}-T_{\infty}\right)
$$

Equation (19) explains that the electric power supplied during the welding is equal to the sum of the radiant heat from the base metal and the convection heat from the particles. Finally, the predictions of particles can be obtained as Equation (20) for $T_{\text {sur }}=T_{\infty}$ and $\eta=1$ :

$$
T_{P, s}=T_{\infty}+\frac{P_{e}-\sigma \varepsilon A_{b, s}\left(T_{b, s}^{4}-T_{\text {sur }}^{4}\right)}{\bar{N} h A_{P, s}}
$$

From the results of the heat transfer with this distribution model of the particles, the overall calculation process can be presented as shown in Figure 7. 


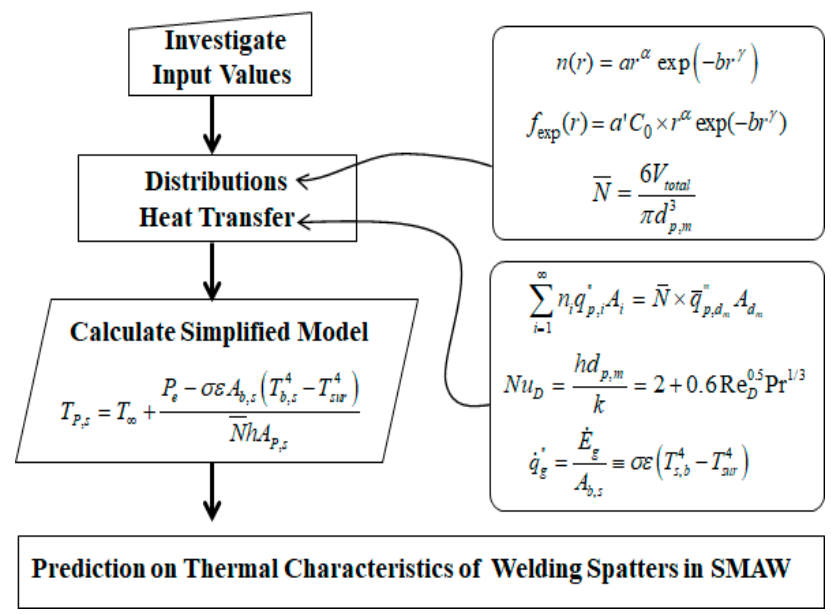

Figure 7. Calculation process of the prediction model.

\section{Results}

To obtain the particle temperature of Equation (20), the main parameters, such as particle mean diameter $\left(d_{p, m}\right)$, the number of particle mean diameter $(\bar{N})$, the electric power $(V I)$ and particle velocity $\left(u_{p}\right)$, should be determined. However, only several simulation results have presented these parameters for a specified condition. Therefore, reliability of the predictions can be obtained from the correlations between the unknown terms, investigated by experiments.

\subsection{Validation of the Presented Model Equation}

Results of the particle temperature are compared to the previous simulation of Urban [5] at $22 \mathrm{~kW}$ $\varepsilon=0.3, \sigma=5.67 \times 10^{-3} \mathrm{~W} / \mathrm{m}^{2} \mathrm{~K}^{4}$ and uarc $=0.0025 \mathrm{~m} / \mathrm{s}$ to validate the accuracy of the prediction model in Equation (20). The surrounding and free stream temperature of $300 \mathrm{~K}$, the particle velocity $\left(u_{p, m}\right)$ of $17.4 \mathrm{~m} / \mathrm{s}$, the base metal area $\left(A_{b, s}\right)$ of $0.04 \mathrm{~m}^{2}$ and the total volume $\left(V_{\text {total }}\right)$ of $2.5 \times 10^{-5} \mathrm{~m}^{3}$ are assumed. As particle diameter $\left(d_{p, m}\right)$ increases, the convective heat transfer coefficient of particle $(h)$ increases with root mean square of $d_{p, m}$ by Equation (15) while the number of particle mean diameter $(\bar{N})$ decreases with third square of $d_{p, m}$ by Equation (12). These induce the particle temperature (T, $\left.T_{p, m}\right)$ to increase and the comparisons between prediction and the previous result are in agreement within $\pm 13 \%$ for $d_{p, m}=1$, 4 , and $7 \mathrm{~mm}$ as shown in Figure 8. However, to predict more accurate the particle temperature using the model presented in this study, the relationship between the electric power, the speed of the welding electrode and the surface area of the base metal should be determined in the steady state.

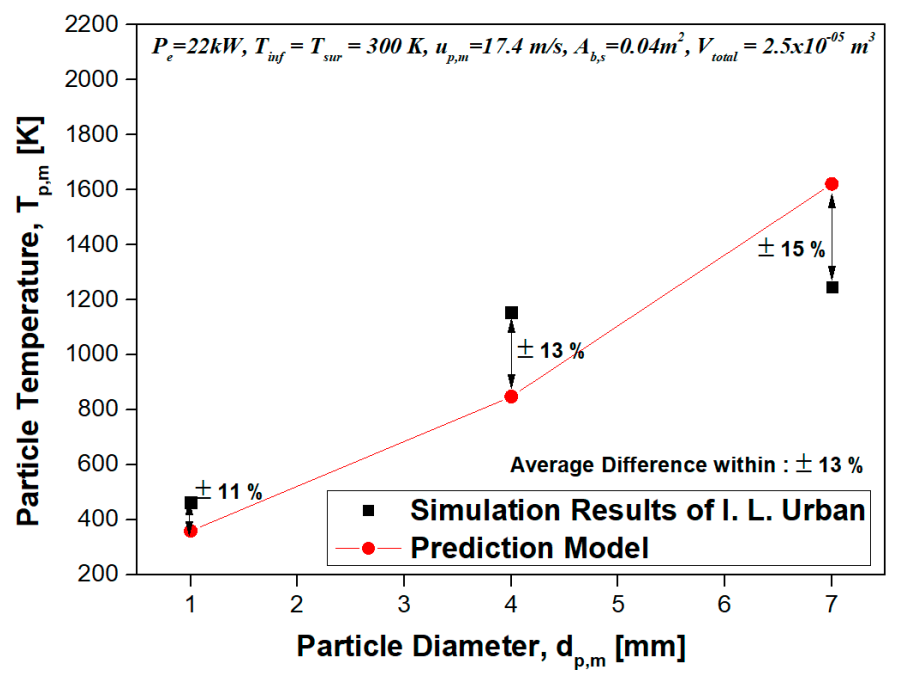

Figure 8. Comparison of the particle temperature of the prediction model with previous results. 


\subsection{Analysis on the Distribution Characteristics of Welding Spatters}

Figure 9 presents that the effects of the normalized distribution $f(r)$ on the change of the distribution coefficient $\gamma$ from 3 to 9 when fixed value of $\alpha=2$. The mean diameters of the particles are in the range of $1.6-6.05 \mathrm{~mm}$ as $\gamma$ decreases. The critical of the particle diameter $\left(d_{p, c}\right)$ which has the risk of igniting the flammable materials is assumed to be $3 \mathrm{~mm}$ by some studies [14], then the distributions from $\gamma=3$ to $\gamma=6$ can cause the fire spread. This result explains that the distribution coefficients are important engineering parameters and the distribution characteristics of the welding spatters significantly influence on the risk of the fire spread.

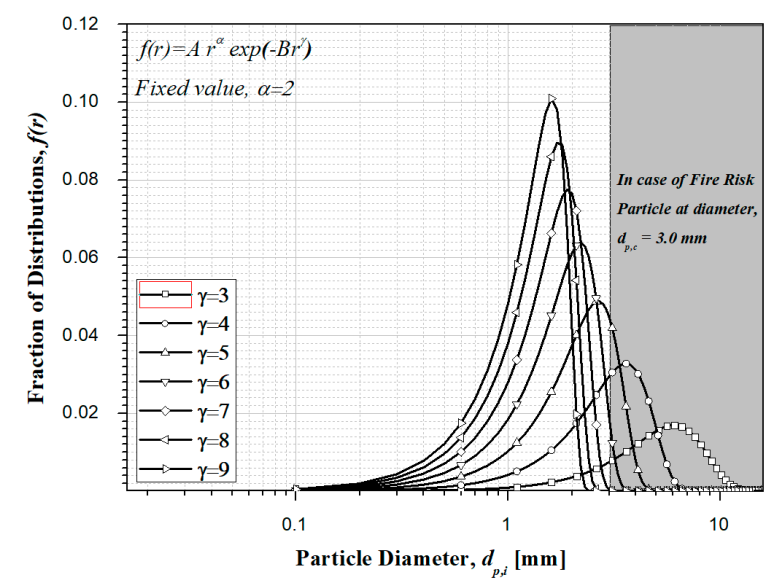

Figure 9. The results of the distribution of the particles for $\alpha=2$ and $\gamma=3,4,5,6,7,8$, and 9 .

Figure 10 denotes that the effects of normalized distribution $f(r)$ on change of the distribution coefficient $\alpha$ from 1 to 7 for $\gamma=4$. The mean diameters of the particles are in the range of 3-4.9 mm, as denoted in Table 1 with the distribution coefficients. In particular, the distribution configurations are sharply shifted to the right when compared to Figure 9. It means that all the distribution features assumed to be greater than $3 \mathrm{~mm}$ in particle size could spread the fire. In this study, the distributions of particles are analyzed with the working conditions such as electrical power, particle velocity, and diameter.

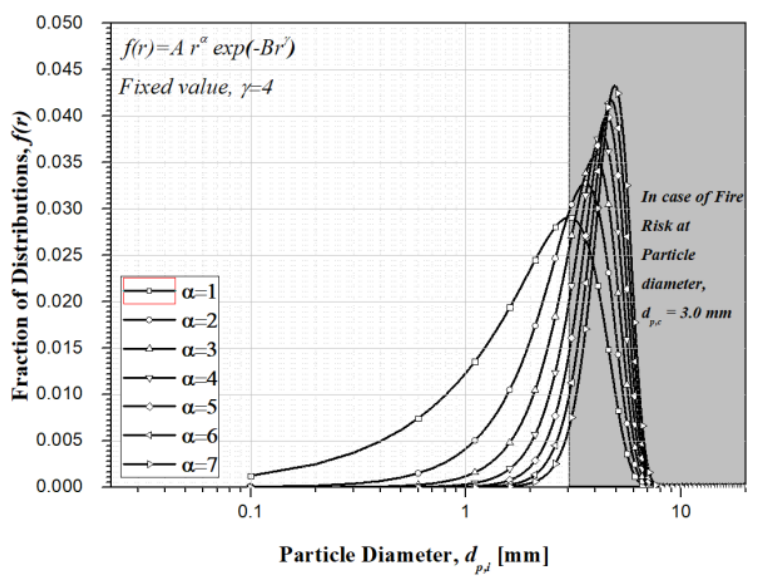

Figure 10. The results of the distribution of the particles for $\gamma=4$ and $\alpha=1,2,3,4,5,6$, and 7 .

\subsection{Analysis on the Thermal Characteristics of Welding Spatters}

Figure 11 shows that effects of the particle temperature $\left(T_{p, m}\right)$, the number of particle mean diameter $(\bar{N})$ and the critical of particle temperature $\left(T_{p, c}\right)$ on the particle mean diameter $\left(d_{p, m}\right)$ change when reaching an electric power $\left(P_{e}\right)$ of $22 \mathrm{~kW}$, the particles velocities $\left(u_{p, m}\right)$ of $17.4 \mathrm{~m} / \mathrm{s}$, the base metal temperature $\left(T_{b, s}\right)$ of $2370 \mathrm{~K}$ (melting temperature of steel [14]), the base metal area $\left(A_{b, s}\right)$ of $0.04 \mathrm{~m}^{2}$ and 
the total volume of the electrode $\left(V_{\text {total }}\right)$ of $2.5 \times 10^{-5} \mathrm{~m}^{3}$ for the $4 \mathrm{~mm}$ electrode's diameter. The $d_{p, m}$ is obtained from the droplet distribution coefficients of $\alpha$ and $\gamma$ in Table 1. The other distribution coefficients $a$ and $b$ can be obtained from Equations (7) and (8). As shown in the table, the particle mean diameter $\left(d_{p, m}\right)$ increases in accordance with $\alpha$ and $\gamma$. It causes the particle temperature $\left(T_{p, m}\right)$ increases as presented in Figure 11 since the number of particle mean diameter $(\bar{N})$ of Equation (12) more rapidly decreases compared to the increase of the convective heat transfer coefficient $(h)$ of Equation (15). In particular, if $T_{p, c}$, which has the risk of igniting the flammable materials assumed with the previous results using Equation (17) (red line in the figure), the fire spread can exist at $d_{p, m}>3.4 \mathrm{~mm}$. Moreover, the 'no ignition' of $d_{p, m}$ is 1.6-3.4 mm for $\alpha=2$ and $\gamma=3-9$ and 3-3.4 $\mathrm{mm}$ for $\gamma=2$ and $\alpha=1-7$. It means that the distribution characteristics is important to estimate the critical of the ignition by the welding spatters. It is a noticeable result that the 'no ignition' can be affected by the distribution coefficients

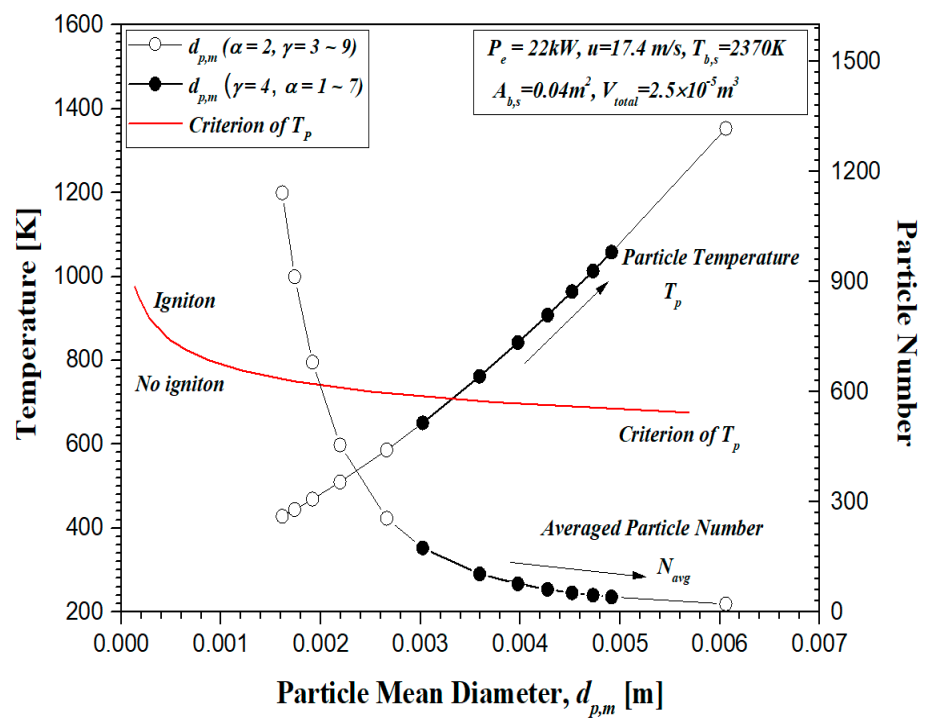

Figure 11. The effects of particle temperature, particle number, and the critical on the particle mean diameter (for ignition of flammable materials).

Figure 12 explains that the effects of the particle temperature $\left(T_{p, m}\right)$ and the convective heat transfer coefficient of particle $(h)$ on the particle velocity $\left(u_{p}\right)$ change when reaching an electric power $\left(P_{e}\right) 22 \mathrm{~kW}$, the base metal temperature $\left(T_{b, s}\right) 2370 \mathrm{~K}$, the base metal area $\left(A_{b, s}\right) 0.04 \mathrm{~m}^{2}$ and the total volume of the electrode $\left(V_{\text {total }}\right) 2.5 \times 10^{-5} \mathrm{~m}^{3}$. The particle temperature $\left(T_{p, m}\right)$ of Equation (20) decreases as the particle velocity $\left(u_{p, m}\right)$ increases since the convective heat transfer coefficient $(h)$ increases in accordance with the Reynolds number $\left(R e_{D}=\rho u_{p, m} d_{p, m} / \mu\right)$ of Equation (15) for each particle mean diameter $\left(d_{p, m}=1 \mathrm{~mm}, 4 \mathrm{~mm}\right.$, and $\left.7 \mathrm{~mm}\right)$. As shown in the figure, the $T_{p, m}$ is higher temperature as $d_{p, m}$ increases for the fixed value of and the total volume of the electrode $\left(V_{\text {total }}\right)$ and the electric power $\left(P_{e}\right)$ in order to converge on the energy equilibrium. Moreover, the critical temperature of $d_{p, m}=1 \mathrm{~mm}$, $4 \mathrm{~mm}$, and $7 \mathrm{~mm}$ can be approximated with $700 \mathrm{~K}, 750 \mathrm{~K}$ and $800 \mathrm{~K}$ from Equation (17). Thus, it is possible to predict that $d_{p, m}=1 \mathrm{~mm}$ satisfies 'no ignition' due to $T_{p, m}<700 \mathrm{~K}$, whereas $d_{p, m}=4 \mathrm{~mm}$ and $7 \mathrm{~mm}$ are 'ignition' due to the minimum values of $T_{p, m}>750 \mathrm{~K}$. However, the maximum particle diameter can be determined by the distribution coefficients $\alpha$ and $\gamma$ (as explained in Figures 4 and 5). Therefore, the fire risk of the welding spatters should consider the maximum welding particle diameter and particle temperature.

Figure 13 shows that effects of the electrical power $\left(P_{e}\right)$ and the particle mean diameter $\left(d_{p, m}\right)$ on the particle temperature $\left(T_{p, m}\right)$ of Equation (20) change when reaching the particle velocity $\left(u_{p, m}\right)$ of $17.4 \mathrm{~m} / \mathrm{s}$. Despite the dependence between $A_{b, s}$ and $P_{e}$, no correlation has been suggested. In this study, the linear fit result of $A_{b, s}$ from the comparison of Urban [30] are assumed with $A_{b, s}=0.0004 \times P_{e}$. As shown in this figure, the number of particles $(\bar{N})$ decreases as particle mean diameter $\left(d_{p, m}\right)$ increases since 
the total volume ( $\left.V_{\text {total }}\right)$ of Equation (12) maintains constant. This causes the surface temperature of particles increase since the overall convective heat transfer coefficient of particles decrease. This means that as more particles are particulate, cooling effects by convection heat improves. Moreover, $d_{p, m}$, which satisfies the critical temperature of the particle $\left(T_{p, c}\right)$, decreases as $P_{e}$ increases. The critical of $d_{p, m}$ and $\bar{N}$ for preventing fire spread by welding spatters are investigated with $d_{p, m}<13 \mathrm{~mm}$ and $\bar{N}>3$ at $2.2 \mathrm{~kW}, d_{p, m}<5.5 \mathrm{~mm}$ and $\bar{N}>25$ at $8.8 \mathrm{~kW}, d_{p, m}<4.0 \mathrm{~mm}$ and $\bar{N}>70$ at $15.4 \mathrm{~kW}, d_{p, m}<2.8 \mathrm{~mm}$ and $\bar{N}>104$ at $22 \mathrm{~kW}$, respectively. However, the exact prediction requires the relations between the electrical power and base metal area as well as the particle mean diameter. Therefore, the results of the surface temperature are only for the analytical results of particle distributions.

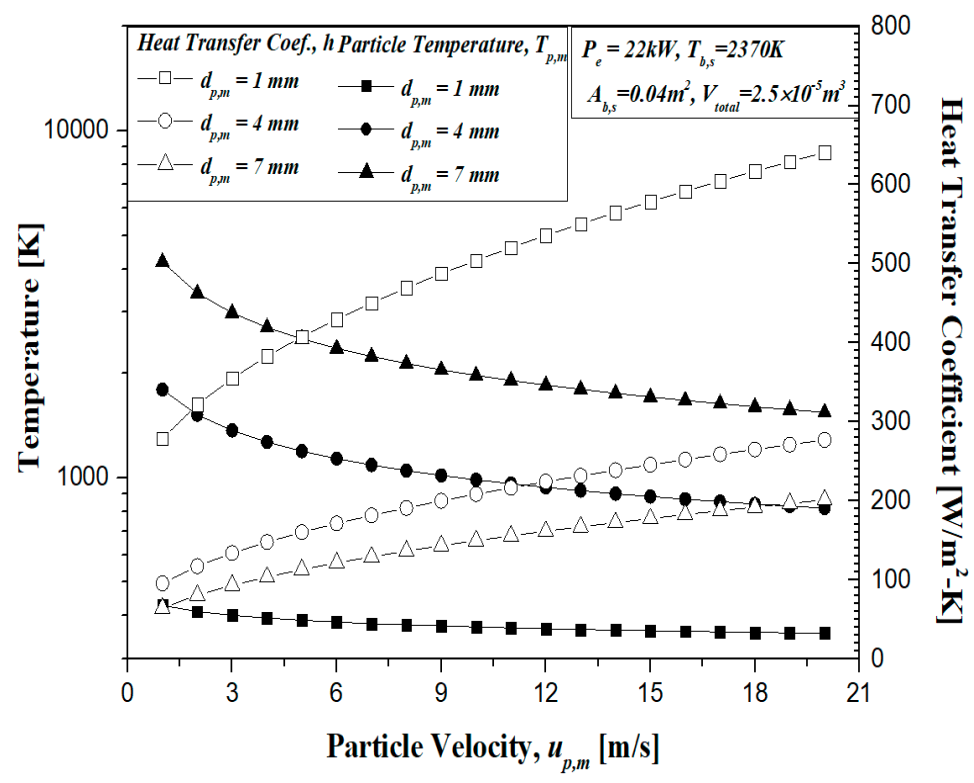

Figure 12. The effects of particle temperature and convective heat transfer coefficient on the particle velocity for $d_{p, m}=1,4$, and $7 \mathrm{~mm}$.

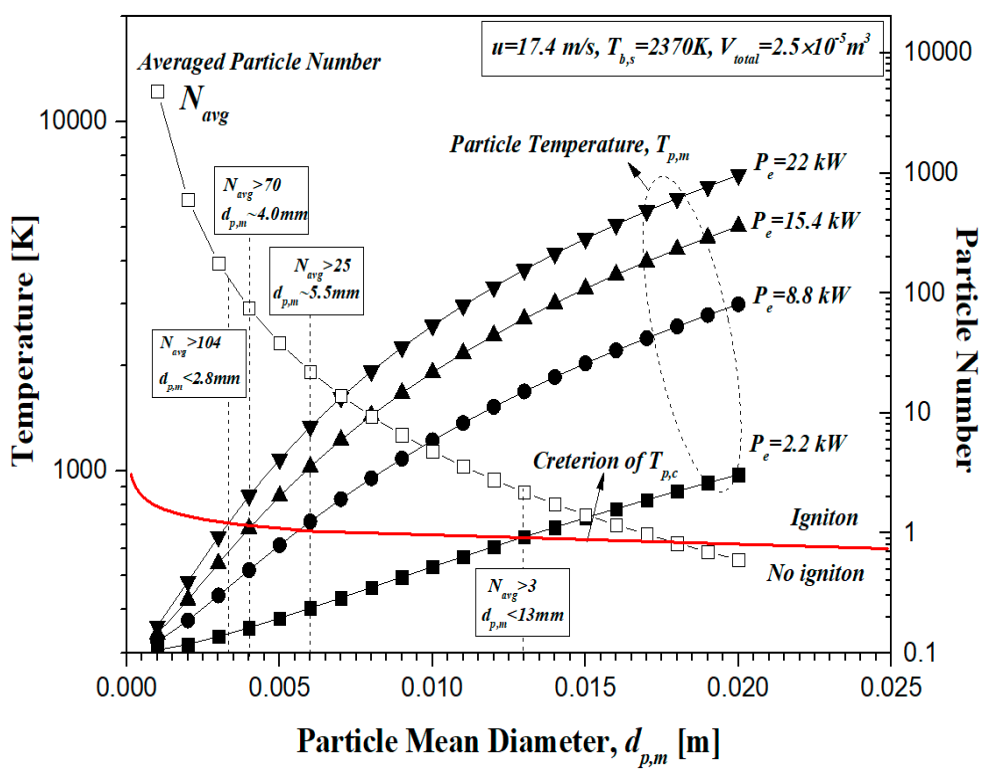

Figure 13. The effects of particle temperature and particle number on the particle mean diameter for $P e=2.2 \mathrm{~kW}, 8.8 \mathrm{~kW}, 15.4 \mathrm{~kW}$ and $22 \mathrm{~kW}$. 


\section{Conclusions}

In this study, a theoretical investigation of the welding spatters by the SMAW is performed. To analyze the fire spread by welding spatters, the critical of particle temperature, which have the risk of igniting the flammable materials, is opted from the previous investigation of Song et al. [14]. The results of this study are summarized as:

Heat transfer equation of the welding spatters are derived from the energy conservation equation. The order of magnitude is performed for the base metal and the particles to present a simplified model. The simulation results of I. U. James are compared to the model equation to validate the accuracy. The prediction and the previous results agree within $\pm 13 \%$. The welding conditions for preventing the fire spread by welding spatters are analyzed with the prediction results with the electrode total volume of $2.5 \times 10^{-5} \mathrm{~m}^{3}$ and the base metal temperature of $2300 \mathrm{~K}$.

The effects of a fire spread on the particles mean diameter in accordance with the distribution coefficients of the welding spatters are investigated with using by a Deirmenjian modified gamma function distribution. The prediction values of the particle temperature linearly increase as the particle mean diameter increases when reaching an electrical power of $22 \mathrm{~kW}$, the particle velocity of $17.4 \mathrm{~m} / \mathrm{s}$ and the base metal area of $0.04 \mathrm{~m}^{2}$. The 'no ignition' region of particle mean diameter exists more widely when the distribution coefficients of $\alpha=2$ and $\gamma=3-9$ than $\gamma=2$ and $\alpha=1-7$. These results validate that not only the particle mean diameter, but the distribution coefficients with the number of particles are significantly influence on the fire spread by welding spatters.

Each particle temperature, which has the particle mean diameter of $1 \mathrm{~mm}, 4 \mathrm{~mm}$, and $7 \mathrm{~mm}$, is predicted in accordance with the variation of particle velocities when the base metal area is $0.04 \mathrm{~m}^{2}$ and electrical power is $22 \mathrm{~kW}$. The surface area increases as $d_{p, m}$ and the velocity increases, resulting in an increase in the convection heat transfer coefficient. In particular, $d_{p, m}=4 \mathrm{~mm}$ and $d_{p, m}=7 \mathrm{~mm}$ for the particle velocity from $1 \mathrm{~m} / \mathrm{s}$ to $20 \mathrm{~m} / \mathrm{s}$ were expected to reach an ignition temperature of more than $750 \mathrm{~K}$.

Finally, the effects of the particle mean diameter $\left(d_{p, m}\right)$ and electrical power $\left(P_{e}\right)$ on the particle temperature are investigated with the assumption that the base metal temperature were linearly proportional to the size of the electric power. it was predicted that the particle temperature would increase proportionally to the size of the particle mean diameter $\left(d_{p, m}\right)$ and the electric power and the number of particle mean diameter $(\bar{N})$ decrease. In addition, the critical of particle diameter $\left(d_{p, c}\right)$ and the number of particle mean diameter $(\bar{N})$ for preventing the fire spread by welding spatters are investigated with $d_{p, m}<13 \mathrm{~mm}$ and $\bar{N}>3$ at $2.2 \mathrm{~kW}, d_{p, m}<5.5 \mathrm{~mm}$ and $\bar{N}>25$ at $8.8 \mathrm{~kW}, d_{p, m}<4.0 \mathrm{~mm}$ and $\bar{N}>70$ at $15.4 \mathrm{~kW}, d_{p, m}<2.8 \mathrm{~mm}$ and $\bar{N}>104$ at $22 \mathrm{~kW}$, respectively.

These results confirm that the simplified model presented in this study could predict the fire spread of the welding spatters depending on the distribution of particles, the particle mean diameter, the number of particles, the particle velocity, and the electrical power.

Author Contributions: Conceptualization, Y.J.S. and W.J.Y.; methodology, W.J.Y; software, Y.J.S.; validation, Y.J.S. and W.J.Y.; formal analysis, W.J.Y.; investigation, Y.J.S. resources, W.J.Y; data curation, W.J.Y.; writing-original draft preparation, W.J.Y.; writing-review and editing, W.J.Y.; visualization, Y.J.S.; supervision, Y.J.S.; project administration, W.J.Y.; funding acquisition, W.J.Y.; All authors have read and agreed to the published version of the manuscript.

Funding: This research was funded by Korea Agency for Infrastructure Technology Advancement, grant number (19CTAP-C151893-01).

Acknowledgments: This research was supported by Korea Agency for Infrastructure Technology Advancement, grant number (19CTAP-C151893-01) and we would like to thank Editage (www.editage.co.kr) for English language editing.

Conflicts of Interest: The authors declare no conflict of interest. The funders had no role in the design of the study; in the collection, analyses, or interpretation of data; in the writing of the manuscript, or in the decision to publish the results. 


\section{References}

1. Hojjati, A.Y.M.; Immarigeon, J. Fusion Bonding/Welding of Thermoplastic Composites. J. Thermoplast. Compos. Mater. 2004, 43, 161-165.

2. Hashemabad, S.G.; Gu, Z.; Ando, T. Flux-less direct soldering of aluminum by ultrasonic surface activation. J. Mater. Process. Technol. 2016, 233, 135-141. [CrossRef]

3. Liu, Y.; Liang, C.; Wei, A.; Jiang, Y.; Tian, Q.; Wu, Y. Solder-free electrical Joule welding of macroscopic graphene assemblies. J. Mater. Today Nano 2018, 3, 1-8. [CrossRef]

4. Narasimhan, P.N.; Mehrotra, S.; Raja, A.R.; Vashista, M.; Yusufzai, M.Z.K. Development of hybrid welding processes incorporating GMAW and SMAW. ICMPC 2019, 18, 2924-2932. [CrossRef]

5. Urban, J.L. Spot Ignition of Natural Fuels by Hot Metal Particles. Ph.D. Thesis, University of California Berkeley, Berkeley, CA, USA, 2017.

6. Janusas, G.; Jutas, A.; Palevicius, A.; Zizys, D.; Barila, A. Static and vibrational analysis of the GMAW and SMAW joints quality. J. Vibroeng. 2012, 14, 1220-1226.

7. Hu, J.; Tsai, H.L. Metal Transfer and Arc Plasma in Gas Metal Arc Welding. J. Heat Transf. 2006, 129, $1025-1035$. [CrossRef]

8. Hu, J.; Tsai, H.L. Heat and mass transfer in gas metal arc welding. Part I: The arc. J. Heat Mass Transf. 2007, 50, 833-846. [CrossRef]

9. Messler, R.W. Principles of Welding: Processes, Physics, Chemistry, and Metallurgy; Wiley: Hoboken, NJ, USA, 2008.

10. DuPont, J.N.; Lippold, J.C.; Kiser, S.D. Welding Metallurgy and Weldability of Nickel-Base Alloys; Wiley: Hoboken, NJ, USA, 2009.

11. Weman, K. Welding Processes Handbook; Cambridge Woodhead Publishing: Cambridge, UK, 2003.

12. Shigeta, M.; Peansukmanee, S.; Kunawong, N. Qualitative and quantitative analyses of arc characteristics in SMAW. Weld. World 2016, 60, 355-361. [CrossRef]

13. Mikkelsen, K. An Experimental Investigation of Ignition Propensity of Hot Work Processes in the Nuclear Industry. Master's Thesis, University of Waterloo, Waterloo, ON, Canada, 2014.

14. Song, J.; Wang, S.; Chen, H. Safety distance for preventing hot particle ignition of building insulation materials. Theor. Appl. Mech. Lett. 2014, 4, 034005. [CrossRef]

15. Hagimoto, N.; Kinoshita, K. Scattering and Igniting Properties of Sparks Generated in an Arc Welding. In Proceedings of the 6th Indo Pacific Congress on Legal Medicine and Forensic Sciences, Kobe, Japan, 26-30 July 1998.

16. NFPA. NFPA Standard 51B: Standard for Fire Prevention During Welding, Cutting, and Other Hot Work; Technical Report; National Fire Protection Association: Quincy, MA, USA, 2009.

17. Kim, Y.S.; Eagar, T.W. Analysis of metal Transfer in Gas Metal Arc Welding. Weld. J. 1991, 72, $269-278$.

18. Lin, Q.; Li, X.; Simpson, S.W. Metal transfer measurements in gas metal arc welding. J. Phys. D Appl. Phys. 2001, 34, 347. [CrossRef]

19. Ahrens, M. Brush, Grass, and Forest Fires; Technical Report November; NFPA: Quincy, MA, USA, 2013.

20. Wakelin, H. Ignition Thresholds for Grassland Fuels and Implications for Activity Controls on Public Conservation Land in Canterbury. Ph.D. Thesis, University of Canterbury, Canterbury, UK, 2010.

21. Choi, S.K.; Yoo, C.D.; Kim, Y.S. Dynamic Simulation of Metal Transfer in GMAW, Part 1: Globular and Spray Transfer Modes. Weld. J. 1998, 34, 347.

22. Wang, F.; Hou, W.K.; Hu, S.J.; Asibu, E.K.; Schultz, W.W.; Wang, P.C. Modelling and analysis of metal transfer in gas metal arc welding. J. Phys. D Appl. Phys. 2003, 36, 1143. [CrossRef]

23. Ingason, H.; Wickstrom, U. Measuring incident radiant heat flux using the plate thermometer. Fire Saf. J. 2006, 42, 161-166. [CrossRef]

24. Viskanta, R. Radiative Transfer in Combustion Systems: Fundamentals and Applications; Begell House: New York, NY, USA, 2005.

25. Deirmendjian, D. Electromagnetic Scattering on Spherical Polydispersions; Elsevier: New York, NY, USA, 1969.

26. You, W.J.; Ryou, H.S. Development and application of a simplified radiative transport equation in water curtain systems. Fire Saf. J. 2018, 96, 124-133. [CrossRef]

27. Sauter, J. Die Grössenbestimmung der in Gemischnebeln von Verbrennungskraftmaschinen vorhandenen Brennstoffteilchen. VDI-Forschungsheft Nr; VDI-Verl: Berlin, Germany, 1926. 
28. Ranz, W.E.; Marshall, W.R. Evaporation from drop, Part 1. Chem. Eng. Prog. 1952, 48, 141-146.

29. Incropera, F.P.; Lavine, A.S.; Bergman, T.L.; DeWitt, D.P. Principles of Heat and Mass Transfer; Wiley: Hoboken, NJ, USA, 2013.

30. Urban, J.L.; Zak, C.D.; Song, J. Smoldering spot ignition of natural fuels by a hot metal particle. Proc. Combust. Inst. 2017, 36, 3211-3218. [CrossRef]

31. Hadden, R.M.; Scott, S. Ignition of Combustible Fuel Beds by Hot Particles: An Experimental and Theoretical Study. Fire Technol. 2011, 47, 341-355. [CrossRef]

32. Bejan, A. Adrian. Convection Heat Transfer; John wiley \& sons: Hoboken, NJ, USA, 2013.

(C) 2020 by the authors. Licensee MDPI, Basel, Switzerland. This article is an open access article distributed under the terms and conditions of the Creative Commons Attribution (CC BY) license (http://creativecommons.org/licenses/by/4.0/). 